\title{
Malaria Prevalence and Associated Factors among Pregnant Women Attending their First Antenatal Care in Kole and Kyenjojo Districts in Uganda
}

\author{
James Ssekitooleko ${ }^{1 *}$, Denis Mubiru ${ }^{2}$, Tinuola Femi Rufus ${ }^{3}$, Catherine Nyakakye ${ }^{2}$, David \\ Kuteesa Mansen ${ }^{4}$ \\ ${ }^{1}$ PhD in Public Health, Texila American University, Uganda \\ ${ }^{2}$ Malaria Consortium, Juba, South Sudan \\ ${ }^{3}$ Federal University, Gusau Zamfara State Nigeria \\ ${ }^{4}$ RTI International, Kampala, Uganda
}

\begin{abstract}
Malaria during pregnancy has negative consequences to both the mother and fetus. In 2019, there were an estimated 33million pregnancies globally, of which 35\% were exposed to malaria in Africa. To avert the consequences, the Uganda Ministry of Health is implementing approaches for effective prevention with intermittent preventive treatment, use Insecticide-Treated Nets (ITN), prompt diagnosis, and treatment through antenatal care (ANC). This study was conducted to determine the prevalence of malaria and associated factors among pregnant women attending their first ANC visit in Kole and Kyenjojo Districts in Uganda. A cross-sectional study design was conducted among 760 randomly selected pregnant women. Quantitative data was collected using a structured questionnaire to gather participants' demographic, obstetric, coverage, and use of malaria preventive methods and laboratory results on malaria, anaemia, and HIV. Data was analyzed using STATA 15. Chi-square, odds ratio, and logistic regression were used to test for associations. The overall prevalence of malaria was $11.1 \%$, varying from $6.8 \%$ in Kyenjojo to $15.3 \%$ in Kole District. Most cases were caused by P. falciparum. Factors associated with malaria were age of mother (aOR: 0.44, 95\% CI: 0.21-0.88), residence in Kyenjojo (aOR: 0.48, 95\% CI: 0.26-0.88), multiparity (aOR: 0.38, 95\% CI: 0.16-0.91), anaemia (aOR: 2.12, 95\% CI: 1.12-4.00) and ITN non-use (aOR: 6.17, 95\% CI: 2.7613.86). Malaria prevalence was low and varied between districts. Age, gravidity, gestational age, and ITN use had a significant association with malaria. Therefore, early screening and identification of mothers at most risk of complications during pregnancy is needed, plus improving ANC.
\end{abstract}

Keywords: Antenatal Care, Malaria in Pregnancy, Pregnant Women, Risk Factors, Uganda.

\section{Introduction}

Malaria remains a major preventable cause of maternal morbidity and adverse birth outcomes in Africa, where an estimated 12.4 million pregnant women were exposed to malaria in 2019 [1]. Although most malaria infections during pregnancy remain asymptomatic in endemic areas, these infections are associated with maternal anaemia and poor birth outcomes. The administration of intermittent preventive treatment with sulfadoxine-pyrimethamine (IPTp-SP), use of Insecticide-Treated Nets (ITNs), and early diagnosis and effective treatment are the fourpronged approaches being implemented by the Uganda Ministry of Health $(\mathrm{MoH})$. Malaria in Uganda is endemic in approximately $95 \%$ of the country, affecting over $90 \%$ of the population. It is rank 4th globally. It is the single most important cause of morbidity and mortality among children under five and 
pregnant women [2]. Every year, malaria accounts for $30-50 \%$ outpatient visits, $15-20 \%$ inpatient admissions, and 9-14\% inpatient deaths [2]. Despite knowing the proven preventive interventions, their uptake has struggled. Therefore, knowing the predictors can aid in the identification and application of control measures.

The factors associated with increased odds of malaria prevalence in pregnant women have been documented in the literature with conflicting findings. Young age, primiparity, no uptake of SP has been reported to significantly increase the odds. Other studies found no such association. In Uganda, there are few studies examining the risk factors in relation to pregnant women attending their first ANC visit. Most studies of malaria during pregnancy have explored factors associated with uptake of antimalarial interventions [3-7] and perceptions of malaria during pregnancy. In this study, maternal and health-related risk factors for malaria were evaluated in a high and low malaria transmission setting in Kole and Kyenjojo districts in Uganda, respectively. This study is one of the first to examine the association between maternal characteristics and malaria in pregnancy in Uganda in two regions of varying malaria transmission.

\section{Materials and Methods}

\section{Study Setting}

The study was conducted among pregnant women attending their first antenatal care clinics in two Districts with varying malaria transmission intensity. Kole District is in Northern Uganda, with a population estimate of 297,479. It has 19 health facilities. In 2020, 14,458 pregnant women in the Kole district attended the first ANC visit, with an average of 1,204 per month. Two high-volume facilities were selected as study sites. Alito HC III and Bala HC III. While Kyenjojo District is in Western Uganda with a population estimate of 525,400 . It has 49 health facilities. In 2020, 21,716 pregnant women attended the first ANC visit with an average of 1,809 per month. Similarly, two high-volume facilities were selected, Katooke HC III and Butunduzi HC III.

\section{Design}

A cross-sectional research design was adopted, and a quantitative data collection method was used. A structured questionnaire was used to collect data from pregnant women. Laboratory samples were collected to test for the presence of malaria parasites, HIV, and anaemia.

\section{Sample Size Determination and Sampling Technique}

The sample size of this study was calculated by using the formula to estimate a single population proportion, with the following assumption, malaria prevalence of $50 \%$, with a confidence level of $95 \%$, and margin of error of 5. A total sample size of 760 pregnant women were selected by using a systematic random sampling technique. The national HMIS form 071: integrated antenatal register was used as the sampling frame. After randomly selecting the start point, thereafter every third unit in the list was included.

\section{Data Collection}

A pre-tested structured questionnaire was administered by trained midwives to obtain data on socio-demographic, obstetric, health-related characteristics of the pregnant women as well as coverage and use of malaria prevention measures. Finger pricked blood samples were taken to detect the presence of malaria parasites (thin and thick blood slides), to measure haemoglobin level using $\mathrm{HemoCue}{ }^{\circledR} 201$ machine, and HIV testing by a trained Phlebotomist.

\section{Data Management and Analysis}

Quantitative data was collected using ODK software, exported to Microsoft Excel, and then transferred to STATA version 15 statistical package for further analysis. The outcome variable for this study was malaria infection 
which was assessed using microscopy. The independent variables include sociodemographic factors (age, marital status, educational status, and occupational status); obstetric factors (gravidity, parity, trimester of pregnancy, history of abortion); malaria prevention measures (ITN ownership and use). Descriptive statistics were done to explain the study population in relation to relevant variables. Both bi-variate and multi-variate logistic regressions were used to assess the association. Odds ratios generated were used to reflect the likelihood of risk factors to malaria prevalence in pregnant women.

\section{Ethical Approval}

Mildmay Uganda Institutional Review Committee (REF 0209-2020), Uganda National Council for Science and Technology, and University Ethical committee Texila American University Guyana approved the study. Written informed consent was obtained from all study participants. Data collected from each participant and results of laboratory tests were kept confidential.

\section{Results}

\section{Socio-Demographic Characteristics of the Pregnant Women}

A total of 760 pregnant women (379 in Kole and 381 in Kyenjojo) were included in this study, with a response rate of $99 \%$. The age of the participants ranged from 15 to 46 years with a median age of 23 , the majority $(41.1 \%)$ of them between 20-24 years. The majority $(94.5 \%)$ of the women were married, and about $77 \%$ of the women completed their primary and secondary level education, and $97 \%$ were farmers. Forty-three percent of the mothers were multigravidae, $50.36 \%$ of them were in their second trimester for their first ANC (Table 1). Over $85 \%$ of pregnant women owned at least one ITN (Figure 1).

Table 1. Background Characteristics of Pregnant Women

\begin{tabular}{|c|c|c|c|c|c|c|}
\hline \multirow[t]{2}{*}{ Socio-demographics } & \multicolumn{2}{|c|}{ Kole $(\mathrm{N}=379)$} & \multicolumn{2}{|c|}{ Kyenjojo (N=381) } & \multicolumn{2}{|c|}{ Total $(N=760)$} \\
\hline & Frequency & Percent $(\%)$ & Frequency & Percent $(\%)$ & Freq & Percent (\%) \\
\hline \multicolumn{7}{|l|}{ Age } \\
\hline Median & 23 & - & - & - & 23 & - \\
\hline Min & 15 & - & 15 & - & 15 & - \\
\hline $\operatorname{Max}$ & 46 & - & 40 & - & 46 & - \\
\hline Mean & 24 & - & 25 & - & 24 & - \\
\hline \multicolumn{7}{|l|}{ Age Group } \\
\hline$\leq 19$ & 88 & 23.2 & 58 & 17.9 & 156 & 20.5 \\
\hline $20-24$ & 153 & 40.4 & 159 & 41.6 & 312 & 41.1 \\
\hline $25-29$ & 80 & 21.1 & 76 & 20.0 & 156 & 20.5 \\
\hline $30-34$ & 36 & 9.5 & 48 & 12.6 & 84 & 11.1 \\
\hline$\geq 35$ & 22 & 5.8 & 30 & 7.9 & 52 & 6.8 \\
\hline \multicolumn{7}{|l|}{ Occupation } \\
\hline Farmers & 368 & 97.1 & 323 & 84.8 & 691 & 90.9 \\
\hline Traders/Professional & 11 & 2.9 & 30 & 7.8 & 41 & 5.4 \\
\hline Unemployed & 0 & 0.0 & 28 & 7.4 & 28 & 3.7 \\
\hline \multicolumn{7}{|l|}{ Education Level } \\
\hline None & 90 & 23.7 & 86 & 22.6 & 176 & 23.2 \\
\hline Primary & 266 & 70.2 & 228 & 59.8 & 494 & 65.0 \\
\hline Secondary or Higher & 23 & 6.1 & 67 & 17.6 & 90 & 11.8 \\
\hline
\end{tabular}




\begin{tabular}{|l|l|l|l|l|l|l|}
\hline Not married & 4 & 1.1 & 38 & 10.0 & 42 & 5.5 \\
\hline Married & 375 & 98.9 & 343 & 90.0 & 718 & 94.5 \\
\hline Gravidity & 142 & 37.5 & 91 & 23.9 & 233 & 30.7 \\
\hline Primigravidae & 57 & 15.0 & 143 & 37.5 & 200 & 26.3 \\
\hline Secundigravidae & 180 & 47.5 & 147 & 38.6 & 327 & 43.0 \\
\hline Multigravidae & Trimester \\
\hline \multicolumn{7}{|l|l|l|}{} \\
\hline 2nt & 186 & 49.1 & 126 & 33.1 & 312 & 41.0 \\
\hline 3rd & 168 & 44.3 & 214 & 56.2 & 382 & 50.3 \\
\hline
\end{tabular}

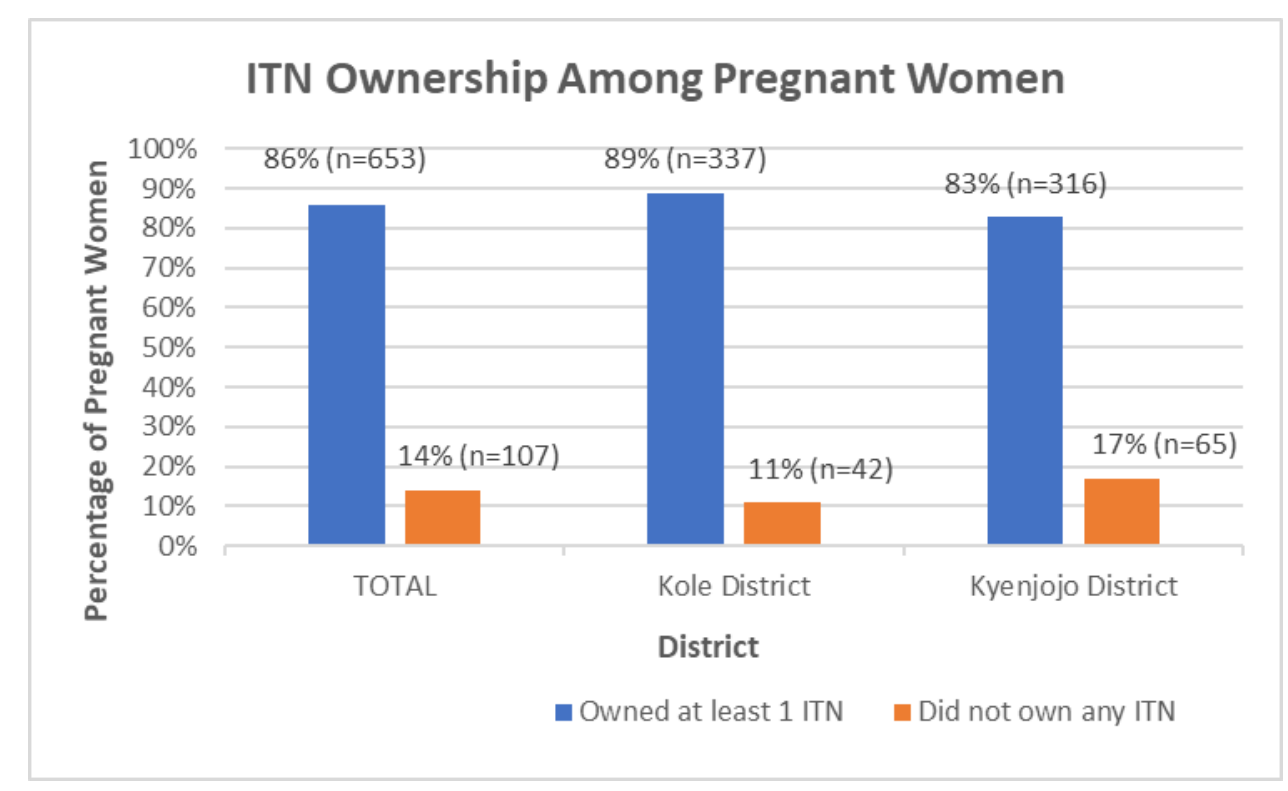

Figure 1. ITN Ownership among Pregnant Women

Prevalence of Malaria Infection among Asymptomatic Pregnant Women

Malaria prevalence in pregnant women as determined by mRDT and microscopy was $18.2 \%$ 95\% CI: $15.6-21.1)$ and $11.1 \%$ (95\% CI: 9.0-13.5) respectively (Figure. 2). High at $15.3 \%$ in Kole and $6.8 \%$ in Kyenjojo. The majority, $96.4 \%$, of cases were due to $\mathrm{P}$. falciparum.

\section{Bi-variate Analysis of Factors associated with Malaria Prevalence among Pregnant Women}

In this study, the age group $(\mathrm{p}<0.0001)$ of the pregnant women was found to be significantly associated with malaria prevalence. More prevalent in the younger age $(15-19$ years $)$ compared to other age groups. The prevalence decreased with increasing age. The other variables (including marital status, educational level attained and occupation) yielded no significant association. The mother's gravidity and gestation period were found to be associated with malaria prevalence $(\mathrm{p}<0.001)$. More prevalent in primigravidae compared to multigravidae. Pregnant women in their $1^{\text {st }}$ trimesters were more suspectable to malaria than their counterpart in $2^{\text {nd }}$ or $3^{\text {rd }}$ trimesters. ITN use was found to be statistically significant at $\mathrm{p}<0.001$, only in Kyenjojo but not in Kole District (Table 2 and 3). 


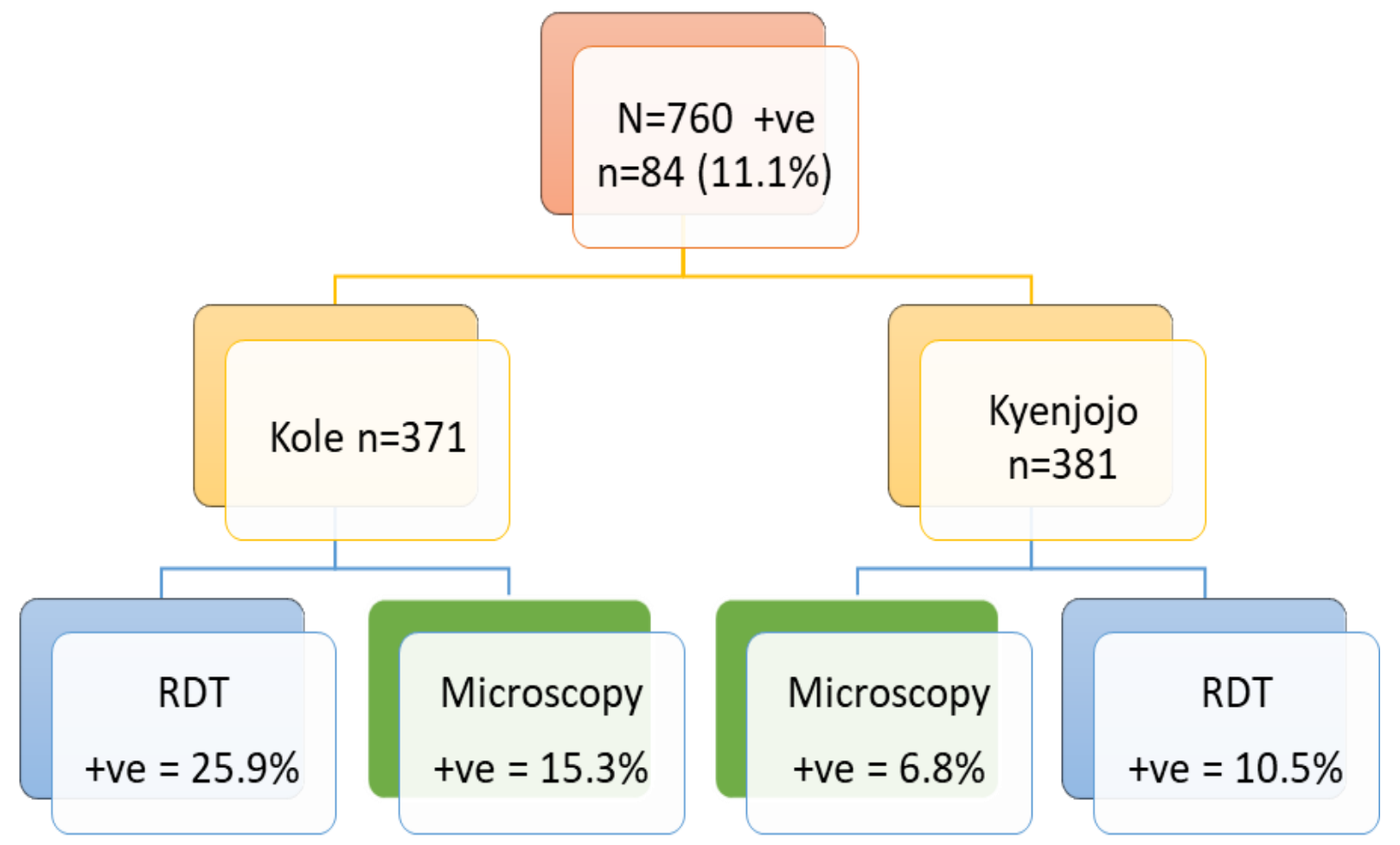

Figure 2. Malaria Prevalence among Pregnant Women by Microscopy and RDT

Table 2. Bivariate Analysis of Socio-demographic Factors associated with Malaria Prevalence in Pregnant Women

\begin{tabular}{|c|c|c|c|c|c|c|}
\hline \multirow{4}{*}{$\begin{array}{l}\text { Socio-demographic } \\
\text { characteristics }\end{array}$} & \multicolumn{2}{|l|}{ Total } & \multicolumn{2}{|c|}{ Kole District } & \multicolumn{2}{|c|}{ Kyenjojo District } \\
\hline & \multicolumn{2}{|c|}{ Malaria (by microscopy) } & \multicolumn{2}{|c|}{ Malaria (by microscopy) } & \multicolumn{2}{|c|}{ Malaria (by microscopy) } \\
\hline & Positive & \multirow[t]{2}{*}{ p-value $* *$} & Positive & \multirow[t]{2}{*}{ p-value $* *$} & Positive & \multirow[t]{2}{*}{ p-value $* *$} \\
\hline & $\mathbf{N}(\%)$ & & $\mathbf{N}(\%)$ & & $\mathbf{N}(\%)$ & \\
\hline \multicolumn{7}{|l|}{ Age (years) } \\
\hline Adolescents (15-19) & $40(25.64)$ & \multirow[t]{2}{*}{$P<0.001 * *$} & $26(29.55)$ & \multirow[t]{2}{*}{$P<0.001 * *$} & $14(20.59)$ & \multirow[t]{2}{*}{$P<0.001 * *$} \\
\hline Adults $(\geq 20)$ & $28(8.97)$ & & $32(11.00)$ & & $12(3.83)$ & \\
\hline \multicolumn{7}{|l|}{ Marital status } \\
\hline Not married & $3(7.14)$ & \multirow[t]{2}{*}{$P=0.611$} & $0(0.00)$ & \multirow[t]{2}{*}{$P=0.393$} & $3(7.9)$ & \multirow[t]{2}{*}{$P=0.734$} \\
\hline Married & $81(11.28)$ & & $58(15.47)$ & & $23(6.7)$ & \\
\hline \multicolumn{7}{|l|}{ Educational level } \\
\hline No education & $12(6.82)$ & \multirow[t]{3}{*}{$P=0.074^{*}$} & $8(8.89)$ & \multirow[t]{3}{*}{$P=0.114$} & $4(4.65)$ & \multirow[t]{3}{*}{$P=0.656$} \\
\hline Primary level & $64(12.96)$ & & $46(17.29)$ & & $18(7.89)$ & \\
\hline Secondary \& higher & $8(9.52)$ & & $4(20.0)$ & & $4(6.25)$ & \\
\hline \multicolumn{7}{|l|}{ Occupation } \\
\hline Farmer & $78(11.29)$ & \multirow[t]{3}{*}{$P=0.82$} & $58(0.00$ & \multirow[t]{3}{*}{$P=0.228$} & $20(6.19)$ & \multirow[t]{3}{*}{$P=0.426$} \\
\hline Traders/Professional & $2(10.71)$ & & $0(0.00)$ & & $3(10.00)$ & \\
\hline Unemployed & $3(7.32)$ & & $0(0.00)$ & & $3(10.71)$ & \\
\hline
\end{tabular}

Note: Row percent used, ** Pearson's chi-square test at alpha $=0.05, \mathrm{~N}$ values are weighted 
Table 3. Bivariate Analysis of Obstetric and Health-Related Factors Associated with Malaria Prevalence in Pregnant Women

\begin{tabular}{|c|c|c|c|c|c|c|}
\hline \multirow{4}{*}{$\begin{array}{l}\text { Obstetric and } \\
\text { other } \\
\text { Characteristics }\end{array}$} & \multicolumn{2}{|l|}{ Total } & \multicolumn{2}{|c|}{ Kole District } & \multicolumn{2}{|c|}{ Kyenjojo District } \\
\hline & \multicolumn{2}{|c|}{ Malaria (by microscopy) } & \multicolumn{2}{|c|}{ Malaria (by microscopy) } & \multicolumn{2}{|c|}{ Malaria (by microscopy) } \\
\hline & Positive & p-value** & Positive & p-value** & Positive & p-value** \\
\hline & \multicolumn{2}{|l|}{$\mathrm{N}(\%)$} & \multicolumn{2}{|l|}{$\mathbf{N}(\%)$} & \multicolumn{2}{|l|}{$\mathbf{N}(\%)$} \\
\hline \multicolumn{7}{|l|}{ Gravidity } \\
\hline Primigravidae & $55(23.61)$ & \multirow[t]{3}{*}{$P<0.001 * *$} & $37(26.06)$ & \multirow[t]{3}{*}{$P<0.001 * *$} & $18(19.78)$ & \multirow[t]{3}{*}{$P<0.001 * *$} \\
\hline Secundigravidae & $14(7.00)$ & & $10(17.54)$ & & $4(2.80)$ & \\
\hline Multigravidae & $15(4.59)$ & & $11(6.11)$ & & $4(2.72)$ & \\
\hline \multicolumn{7}{|l|}{ Gestation period } \\
\hline First Trimester & $56(17.95)$ & \multirow[t]{3}{*}{$P<0.001 * *$} & $41(22.04)$ & \multirow[t]{3}{*}{$P=0.002 * *$} & $15(11.90)$ & \multirow[t]{3}{*}{$P=0.024^{*}$} \\
\hline Second Trimester & $24(6.28)$ & & $15(8.93)$ & & $9(4.21)$ & \\
\hline Third Trimester & $4(6.06)$ & & $2(8.00)$ & & $2(4.88)$ & \\
\hline \multicolumn{7}{|l|}{ HIV serostatus } \\
\hline Positive & $4(50.0)$ & \multirow[t]{2}{*}{$P<0.001 * *$} & $4(50.00)$ & \multirow[t]{2}{*}{$P=0.022 *$} & $0(0.00)$ & \multirow[t]{2}{*}{$P=0.296$} \\
\hline Negative & $80(10.6)$ & & $80(10.6)$ & & $26(12.31)$ & \\
\hline \multicolumn{7}{|c|}{ Haemoglobin levels } \\
\hline Any anaemia & $56(17.95)$ & \multirow[t]{2}{*}{$P<0.001$ ** } & $26(25.49)$ & \multirow[t]{2}{*}{$P=0.001 * *$} & $10(4.85)$ & \multirow[t]{2}{*}{$P<0.001 * *$} \\
\hline No anaemia & $24(6.28)$ & & $32(11.55)$ & & $16(4.85)$ & \\
\hline \multicolumn{7}{|l|}{ ITN ownership } \\
\hline Yes & $67(10.26)$ & \multirow[t]{2}{*}{$P=0.085^{*}$} & $49(14.54)$ & \multirow[t]{2}{*}{$P=0.242$} & $18(5.70)$ & \multirow[t]{2}{*}{$P=0.054^{*}$} \\
\hline No & $17(15.89)$ & & $9(21.43)$ & & $8(12.31)$ & \\
\hline \multicolumn{7}{|c|}{ Number of ITN owned } \\
\hline None & $17(15.89)$ & $P=0.005 * *$ & $9(21.43)$ & $P<0.001 * *$ & $8(12.31)$ & $P=0.072$ \\
\hline One & $41(14.49)$ & & $29(20.86)$ & & $12(8.33)$ & \\
\hline Two & $21(9.77)$ & & $18(16.98)$ & & $3(2.75)$ & \\
\hline Three \& more & $5(3.23)$ & & $2(2.17)$ & & $3(4.76)$ & \\
\hline ITN Use & & & & & & \\
\hline Yes & $50(8.25)$ & $P<0.001 * *$ & $43(13.87)$ & $P=0.253$ & $7(2.36)$ & $P<0.001 * *$ \\
\hline No & $17(36.17)$ & & $6(22.2)$ & & $11(55.0)$ & \\
\hline
\end{tabular}

Note: Row percent used, ** Pearson's chi-square test at alpha $=0.05, \mathrm{~N}$ values are weighted

Multi-variate Analysis of Factors Associated with Malaria Prevalence among Pregnant Women

Multiple logistic regression analysis was performed to identify independent predictors of malaria among pregnant women. Ten explanatory variables that were associated with malaria in bivariable analyses at $10 \%$ level of significance were entered into the multiple logistic regression models. In the last step of the analysis, two variables were excluded. Age, area of residence, gravidity, gestation age, and use of ITN showed a significant association with the prevalence of malaria at $\mathrm{p}<0.05$. Accordingly, being an adult (older mothers aged $\geq 20$ years or more) had a $56 \%$ (AOR: 0.44, 95\% CI: 0.21-0.88) protection from malaria infection compared to adolescents (young mothers 15-19 years). Staying in Kyenjojo district had a 52\% (AOR: 0.48, 95\% CI: 0.26-0.88) less likely to be infected with malaria compared to pregnant women in the Kole district. Multigravidae 62\% (AOR: 0.38, 
95\% CI: 0.16-0.91) less likely to be infected with malaria compared to Primigravidae and Secundigravidae. Women not using ITNs were
6 times (AOR: 6.17, 95\% CI: 2.76-13.86) more likely to be infected with malaria as compared to those using ITNs (Table 4).

Table 4. Multi-variate Analysis of Risk Factors Associated with Malaria Prevalence in Pregnant Women

\begin{tabular}{|c|c|c|c|c|c|c|}
\hline \multirow[t]{2}{*}{ Factors } & \multicolumn{3}{|c|}{ Crude Estimates } & \multicolumn{3}{|c|}{ Adjusted Estimates } \\
\hline & OR & $95 \% \mathrm{CI}$ & p-value & aOR & $95 \% \mathrm{CI}$ & p-value \\
\hline \multicolumn{7}{|l|}{ Age in years } \\
\hline Adolesents (15-19) & 1 & - & - & 1 & - & - \\
\hline Adults (>20 yrs) & 0.23 & $0.14-0.37$ & $P<0.001 * *$ & 0.44 & $0.21-0.88$ & $P=0.021 *$ \\
\hline \multicolumn{7}{|l|}{ Location } \\
\hline Kole & 1 & - & - & 1 & - & - \\
\hline Kyenjojo & 0.23 & $0.14-0.66$ & $P<0.001 * *$ & 0.48 & $0.26-0.88$ & $P=0.018^{*}$ \\
\hline \multicolumn{7}{|l|}{ Educational level } \\
\hline No education & 1 & - & - & 1 & - & - \\
\hline Primary & 2.03 & $1.07-3.87$ & $P=0.03^{*}$ & 1.26 & $0.55-2.91$ & $P=0.589$ \\
\hline Secondary/Higher & 1.44 & $0.56-3.66$ & $P=0.446$ & 1.23 & $0.40-3.77$ & $P=0.718$ \\
\hline \multicolumn{7}{|l|}{ Gravidity } \\
\hline Primigravidae & 1 & - & - & 1 & - & - \\
\hline Secundigravidae & 0.24 & $0.13-0.45$ & $P<0.001 * *$ & 0.68 & $0.30-1.58$ & $P=0.372$ \\
\hline Multigravidae & 0.16 & $0.09-0.28$ & $P<0.001$ ** & 0.38 & $0.16-0.91$ & $P=0.03$ ** \\
\hline \multicolumn{7}{|l|}{ Gestation period } \\
\hline First Trimester & 1 & - & - & 1 & - & - \\
\hline Second Trimester & 0.31 & $0.19-0.51$ & $P<0.001$ ** & 0.51 & $0.27-0.96$ & $P=0.035^{* *}$ \\
\hline Third Trimester & 10.29 & $0.10-0.84$ & $P=0.023$ & 0.58 & $0.12-2.62$ & $P=0.476$ \\
\hline \multicolumn{7}{|l|}{ HIV serostatus } \\
\hline Positive & 1 & - & - & 1 & - & - \\
\hline Negative & 0.12 & $0.03-0.49$ & $P=0.003 * *$ & 0.08 & $0.01-0.43$ & $P=0.003 * *$ \\
\hline \multicolumn{7}{|l|}{ Haemoglobin level } \\
\hline No anaemia & 1 & - & - & 1 & - & - \\
\hline Any anaemia & 3.58 & $2.22-5.77$ & $P<0.001 * *$ & 2.12 & $1.12-4.00$ & $P=0.021^{*}$ \\
\hline \multicolumn{7}{|l|}{ ITN Use } \\
\hline Yes & 1 & - & - & 1 & - & - \\
\hline No & 6.30 & $3.25-12.2$ & $P<0.001$ ** & 6.27 & $2.82-13.94$ & $P<0.001 * *$ \\
\hline
\end{tabular}

Note: Row percent used, $* *$ Pearson's chi square test at alpha $=0.05, \mathrm{~N}$ values are weighted

\section{Discussion}

The overall prevalence of malaria was found to be $11.1 \%$, with prevalence higher in Kole district at $15.3 \%$ compared to $6.8 \%$ in Kyenjojo district $(\mathrm{P}<0.001)$. The results are similar to studies conducted in the Central region of Uganda (10\%) [8], West Ethiopia (10.8\%) [9], Sudan (13.7\%) [10], a systematic review and meta-analysis in Ethiopia $12.7 \%$ [11] and in
Ghana (8.9\%) [12]. However, our results were higher than studies conducted in Ethiopia (2.83\%) [13], coastal Ghana (5\%) [14], SouthWest Nigeria (7.7\%) [15], Southern Laos (8.3\%) [16] and India (5.4\%) [17]. This difference might be attributed to the difference in geographical location among the study areas. On the other hand, the prevalence in our study was found to be much lower than the findings from one study conducted in Uganda, which 
showed a prevalence that varied from varied from 20\% in Mulago [18], 21.3\% in Mbale [19] to $66 \%$ in Tororo [20]. This difference may be due to the scale-up of prevention measures like increased ITN, in our study, over $83 \%$ coverage of at least 1 ITN and use of $92 \%$ for those mothers who had access.

Factors associated with the prevalence of malaria among pregnant women - at multivariate analysis, age of the pregnant woman, residence/district, gravidity, gestational age, anaemia, and ITN utilization were found to be significantly associated with malaria infection. Age of the mother - In this study, mothers with an increased age were found to have lower odds of developing malaria infection. This is in line with studies conducted in different tropical African countries [21, 22, 23] which reported pregnant women of a young age are at the greatest risk of malaria infection. This may be attributed to mothers with increased age have better exposure, good awareness about malaria prevention, and previous frequent malaria exposures leading to developing immunity to malaria. However, according to the studies conducted in Ethiopia [24], and Sudan [10], age had no significant association with malaria infection.

Gravidity and gestational age as risk factors to MiP - In our study, pregnant women who were in the $1^{\text {st }}$ trimester were at increased odds of developing malaria infection compared to mothers in their $2^{\text {nd }}$ or $3^{\text {rd }}$ trimester. Besides this, prime gravidae had increased odds of malaria infection compared to the multigravid. Similar results were found from studies done in sub-Saharan Africa countries [24-27], which showed a higher risk of malaria infection among primigravidae than multigravidae. Low risk of malaria among multigravidae mothers may be associated with the development of preimmunity to malaria with increased gravidity and previous exposures. Primigravidae mothers lack antiadhesion antibodies against CSA binding parasites, which develop only after successive pregnancies, and this makes them more susceptible to infection [28].

ITN - Not using ITN in our study increased the odds of developing malaria infection during pregnancy. Our finding was also in agreement with the study conducted in Nigeria [24] and Ethiopia [21], which showed that the use of bed nets had an impact on decreasing infection. The possible explanation could be ITNs effectively reduce human-mosquito contact, which can prevent diseases. In this study, the coverage of ITNs was very high in both districts (Kole at $89 \%$ and Kyenjojo at $83 \%$ ), while ITN use among those who owned at least 1 , ITN was very good at $93.7 \%$. This may explain the high protective effect observed in our study. However, our results are different from those reported in Ghana, where ITN use was associated with a higher risk of malaria parasitaemia [29]. However, this surprising result was attributed to the state of the ITN used because about $12 \%$ of participants in their study reported the nets in which they slept were torn.

\section{Conclusion}

The study findings show that malaria prevalence among pregnant women in both districts was low, varying among the two districts - higher in Kole districts and lower in Kyenjojo and $\mathrm{P}$. falciparum is the most predominant Plasmodium species. Age of pregnant woman, gravidity, gestational age, ITN use, and anaemia had a significant association with malaria infection. The timing of the first visit for ANC is critical for early screening and identification of mothers at most risk of complications during pregnancy, including malaria. Hence any mother screened with these risks' factors should be considered "most at risk" and included as part of the criteria for admission of those with them. There is value if the information on the prevalence of malaria at the ANC booking becomes more widely available through simple screening as done in this study were to be adopted in areas for broader malaria surveillance and monitoring deployment of interventions. 


\section{Acknowledgements}

Sincere gratitude goes to my supervisor Prof Femi Rufus Tinuola at Federal University, Gusau Zamfara State Nigeria, for his genuine and intellectual advice in this study. I am grateful to the study participants for their voluntary involvement and for providing the required information. Finally, thanks go to

\section{References}

[1] WHO. World malaria report 2020 Geneva: World Health Organization. Available from: https://www.who.int/malaria/publications/worldmalaria-report-2020/en/.

[2] Uganda Malaria Reduction and Elimination Strategic Plan 2021-2025. Ministry of Health. https://www.health.go.ug/cause/the-uganda-malariareduction-strategic-plan-2014-2020/.

[3] Pell C, et al., 2011. Social and cultural factors affecting uptake of interventions for malaria in pregnancy in Africa: a systematic review of the qualitative research. Public Library of Science One. 6: e22452. Available from: https://www.ncbi.nlm.nih.gov/pmc/articles/PMC314 0529/pdf/pone.0022452.pdf.

[4] Mubyazi G, et al., 2005. Intermittent preventive treatment of malaria during pregnancy: a qualitative study of knowledge, attitudes and practices of district health managers, antenatal care staff and pregnant women in Korogwe District, North-Eastern Tanzania. Malaria Journal; 4:31. Available from: https://www.ncbi.nlm.nih.gov/pmc/articles/PMC118 7919/pdf/1475-2875-4-31.pdf.

[5] Muhumuza E, et al., 2016. Factors associated with the use of malaria control interventions by pregnant women in Buwunga sub-county, Bugiri District. Malaria Journal; 15:342. Available from: https://www.ncbi.nlm.nih.gov/pmc/articles/PMC493 2743/pdf/12936_2016_Article_1407.pdf.

[6] Hill J, et al., 2013. Factors affecting the delivery, access, and use of interventions to prevent malaria in pregnancy in sub-Saharan Africa: a systematic review and meta-analysis. Public Library of Science Medicine Available from: midwives, laboratory technicians, and malaria focal persons in the study sites for their support.

\section{Conflict of Interest}

The authors declare no conflicts of interest in this work.

https://www.ncbi.nlm.nih.gov/pmc/articles/PMC372 0261/pdf/pmed.1001488.pdf.

[7] Sangare L.R., et al., 2010. Determinants of use of intermittent preventive treatment of malaria in pregnancy: Jinja, Uganda. Public Library of Science One. 5: e15066. Available from: https://www.ncbi.nlm.nih.gov/pmc/articles/PMC299 3958/pdf/pone.0015066.pdf.

[8] Ndibazza, J, et al., 2013. Associations between maternal helminth and malaria infections in pregnancy and clinical malaria in the offspring: a birth cohort in entebbe, Uganda. The Journal of infectious diseases, 208(12), doi: 10.1093/infdis/jit397.

https://www.ncbi.nlm.nih.gov/pmc/articles/PMC383 6463/pdf/jit397.pdf.

[9] Geleta G, et al., 2017. Prevalence of malaria and frequency of severe symptoms among pregnant women in Pawe hospital, Northwestern Ethiopia. Annals of Clinical Pathology. 5:1109. Available from:

https://www.jscimedcentral.com/Pathology/patholog y-5-1109.pdf.

[10] Adam I, Khamis AH, Elbashir MI, 2005. Prevalence and risk factors for Plasmodium falciparum malaria in pregnant women of eastern Sudan. Malaria Journal. ;4(1):18. Available from: https://bmcinfectdis.biomedcentral.com/articles/10.1 186/s12879-020-05289-9.

[11] Tegegne $Y$, et al., 2019. The prevalence of malaria among pregnant women in Ethiopia: a systematic review and meta-analysis. Journal of Parasitology Research. Available from: https://www.ncbi.nlm.nih.gov/pmc/articles/PMC652 1389/pdf/JPR2019-8396091.pdf.

[12]Linda A.F, et al., 2020. A multicenter study of the prevalence and risk factors of malaria and 
anemia among pregnant women at first antenatal care visit in Ghana. Public Library of Science One. 15(8): e0238077. Available from: https://www.ncbi.nlm.nih.gov/pmc/articles/PMC744 4479/pdf/pone.0238077.pdf.

[13] Asmamaw T, et al., 2013. Prevalence of malaria and HIV among pregnant women attending antenatal clinics at felege hiwot referral hospital and Addis zemen health center. International Journal Life Science Biotechnology Pharmaceutical Research. 3;2(1-13). Available from: http://www.ijlbpr.com/index.php?m=content\&c=ind ex\&a=show\&catid=120\&id=86.

[14] Ahenkorah B, et al., 2020. Parasitic infections among pregnant women at first antenatal care visit in northern Ghana: A study of prevalence and associated factors. Public Library of Science One. 15(7): e0236514. Available from: https://www.ncbi.nlm.nih.gov/pmc/articles/PMC738 0595/pdf/pone.0236514.pdf.

[15] Agomo C.O, et al., 2009. Prevalence of Malaria in Pregnant Women in Lagos, South-West Nigeria. Korean Journal Parasitology. 179-183. P doi: 10.3347/kjp.2009.47.2.179. Available from: https://www.ncbi.nlm.nih.gov/pmc/articles/PMC268 8802/pdf/kjp-47-179.pdf.

[16] Briand V, et al., 2016. Prevalence of malaria in pregnancy in southern Laos: a cross-sectional survey. Malaria Journal. ;15(1):436. Available from:

https://www.ncbi.nlm.nih.gov/pmc/articles/PMC500 $2160 /$.

[17] Sohail M, et al., 2015. Prevalence of malaria infection and risk factors associated with Anaemia among pregnant women in Semiurban Community of Hazaribag, Jharkhand, India. Biomed Research International::740512. Available from: https://www.ncbi.nlm.nih.gov/pmc/articles/PMC469 $1455 /$.

[18] Namusoke, F, et al., 2010. Malaria burden in pregnancy at Mulago national referral hospital in Kampala, Uganda. Malaria Research and Treatment. doi: 10.4061/2010/913857. Available from:

https://www.ncbi.nlm.nih.gov/pmc/articles/PMC327 $7833 /$.
[19] Kyabayinze, D. J, et al., 2011. Placental Plasmodium falciparum malaria infection: operational accuracy of HRP2 rapid diagnostic tests in a malaria-endemic setting. Malaria Journal, 10(1), $306 . \quad$ Available from: https://www.ncbi.nlm.nih.gov/pmc/articles/PMC320 6496/.

[20] Arinaitwe, E, et al., 2013. Intermittent preventive therapy with sulfadoxine-pyrimethamine for malaria in pregnancy: a cross-sectional study from Tororo, Uganda. Public Library of Science One, 8(9), e73073. Available from: https://www.ncbi.nlm.nih.gov/pmc/articles/PMC376 $2885 /$.

[21] Gontie G.B, Wolde H.F, Baraki A.G., 2020. Prevalence and associated factors of malaria among pregnant women in Sherkole district, Benishangul Gumuz regional state, West Ethiopia. BioMed Central Infectious Diseases. 20:573. Available from: https://bmcinfectdis.biomedcentral.com/articles/10.1 186/s12879-020-05289.

[22] Ouedraogo M, et al., 2019. Utilization of key preventive measures for pregnancy complications and malaria among women in Jimma Zone, Ethiopia. BioMed Central Public Health. 19: [22] 1443. Available from: https://www.ncbi.nlm.nih.gov/pmc/articles/PMC682 $7171 /$.

[23] De Beaudrap P, et al., 2013. Impact of malaria during pregnancy-on-pregnancy outcomes in an Uganda prospective cohort with intensive malaria screening and prompt treatment. Malaria Journal. 12: $139 . \quad$ Available from: https://www.ncbi.nlm.nih.gov/pmc/articles/PMC475 4923/.

[24]Nega D, et al., 2015. Anemia associated with asymptomatic malaria among pregnant women in the rural surroundings of Arba Minch Town, South Ethiopia. BioMed Central Research Notes. doi:10.1186/s13104-015-1081-4. Available from: https://www.ncbi.nlm.nih.gov/pmc/articles/PMC439 $2875 /$.

[25] Yimam Y, et al., 2021. A systematic review and meta-analysis of asymptomatic malaria infection in pregnant women in Sub-Saharan Africa: A challenge for malaria elimination efforts. Public Library of 
Science One. 216(4). Available from: https://www.ncbi.nlm.nih.gov/pmc/articles/PMC801 $6273 /$.

[26] Ofori M, et al., 2009. Pregnancy-associated malaria in a rural community of Ghana. Ghana Medical Journal. 43(1):13-8. Available from: https://www.ncbi.nlm.nih.gov/pmc/articles/PMC270 9171/.

[27] Okiring, J, et al., 2019. Household and maternal risk factors for malaria in pregnancy in a highly endemic area of Uganda: a prospective cohort study. Malaria Journal, 18(1), 144. Available from: https://www.ncbi.nlm.nih.gov/pmc/articles/PMC648 0498/.

[28] Van Eijk, A.M, et al., 2015. Prevalence of malaria infection in pregnant women compared with children for tracking malaria transmission in subSaharan Africa: a systematic review and metaanalysis. The Lancet Global Health, 3(10). Available from: https://www.ncbi.nlm.nih.gov/pmc/articles/PMC467 3091/.

[29] Kwame D.D, et al., 2020. Epidemiology of malaria among pregnant women during their first antenatal clinic visit in the middle belt of Ghana: a cross sectional study. Malaria Journal. 19: 381. Available from: https://www.ncbi.nlm.nih.gov/pmc/articles/PMC758 $5211 /$. 